www.jmscr.igmpublication.org

Index Copernicus Value: 79.54

ISSN (e)-2347-176x ISSN (p) 2455-0450

crossref DOI: https://dx.doi.org/10.18535/jmscr/v7i4.172

\title{
A Pilot Study to Evaluate the Efficacy of Cranberry Extract Supplements in Prevention of Recurrent UTI in Female Patients
}

\author{
Authors

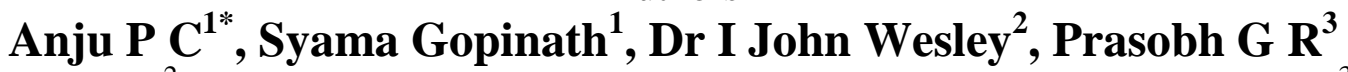 \\ ${ }^{1}$ Pharm D students, ${ }^{2}$ Head of the Department and Professor of Dept of Pharmacy Practice, ${ }^{3}$ Principal \\ Sree Krishna College of Pharmacy and Research Centre, Trivandrum, Kerala, India \\ *Corresponding Author \\ Anju P C \\ Email: anjupc94@gmail.com
}

\begin{abstract}
Introduction: UTI s are usually the result of gram negative bacteraemia. It can be classified as complicated or complicated or primary or recurrent. Recurrent UTI may be relapses or reinfection. Female gender is considered as a main risk factor in recurrent UTI. Long term antibiotics are usually prescribed in recurrent infection. But this will increase the risk of development of resistance. Cranberry supplements are used for prevention of UTI $s$ and they are having the efficacy of preventing the bacterial adherence to the bladder wall. This study aims to evaluate the efficacy of cranberry extract supplements in prevention of recurrent UTI in female patients.

Method: Prospective observational study. 20 Patients with UTI and satisfying the study criteria are selected and are advised to take cranberry extract supplements after completing the antibiotic therapy. Four follow up $s$ done and symptom assessment and microbiological evaluation performed during initial visit and each follow ups.

Result: Among the selected patients 17 patients completed the study. From this 13 patients showed effective response to the therapy and 4 patients developed recurrence of infection.

Conclusion: From the study result it can be concluded that for female patients with recurrent UTI, Cranberry extract supplements can play major role in the prevention of further recurrence.

Keywords: Urinary tract infections, Females, E Coli, Recurrent infections, Symptom assessment, Microbiological evaluation, Cranberry supplements.
\end{abstract}

\section{Introduction}

Urinary tract infections are one of the leading cause of gram negative bacteraemia for patients of all ages. The infection of the bladder and urethra are referred to as the infection of the lower urinary tract whereas the kidney and ureter infection is an indication of upper urinary tract infection. UTI can be asymptomatic or symptomatic characterized by a wide spectrum of symptoms ranging from mild burning micturition to bacteraemia, sepsis or even death. Other complications caused by UTI's are bladder infection (cystitis), urethral infection (urethritis), kidney infection (pyelonephritis) and infection of the ureter (ureteritis). UTI's can be classified as uncomplicated or complicated (based on the factor that triggers the infection or primary or recurrent (depending on the nature of occurrence). Recurrent UTI's are common in women and are 
associated with considerable morbidity and health care use. The clinical features, diagnostic tests and causative organisms are often similar to those of single cases of UTI although there are additional treatment strategies and prevention measures to consider with recurrent UTI.

Recurrent UTI's include relapses (symptomatic recurrent UTI'S with the same organism following adequate therapy) and re infection(recurrent UTI's with previously isolated bacteria after treatment and with a negative intervening urine culture for a recurrent UTI caused by a second bacterial isolate).Most recurrent UTI's are thought to be caused by re infection with same organism. Recurrent UTI in adult women is usually treated with long term low dose Antibiotics and current national and International guideline recommend this as the "gold standard" preventive treatment. Although they are reasonably effective long term antibiotics can result in developing resistance in bacteria. This has lead clinicians and patients alike to explore potential non antibiotic option for recurrent UTI prevention.

Cranberries have been used widely for several decades for the prevention and treatment of UTI. No definite mechanism of action has been established in the prevention of UTI however the main suggestion is that cranberries prevent bacteria from adhering to uro epithelial cells that line the bladder wall.

So in this study we are evaluating the efficacy of cranberry extract supplements in prevention of recurrent UTI in female patients.

\section{Methodology}

The study consists of 20 female patients from the Department of Urology in a tertiary care hospital who were diagnosed with symptoms of UTI and satisfying the inclusion and exclusion criteria's. After the complete course of antibiotic therapy Cranberry extract supplements were administered to the patients for about sixty days. Regular follow up's were done after 2 weeks 1 month 3 months and the 6th month after administering cranberry supplement. A suitably designed proforma was used to evaluate the symptoms and microbiological evaluation at the time of initial visit and each follow up's. The symptoms like Frequency, Urgency, Pain or burning pain, voiding difficulty, lower abdominal pain, low back pain and Haematuria were mainly assessed and were categorized into Nil, Mild, Moderate and Severe. The results were then obtained through statistical analysis.

\section{Inclusion Criteria}

- Females of age between 15-70

- Patients willing to participate in the study

- Clinically reported UTI

- Patient with lifestyle diseases

- H/o of recurrent UTI

\section{Exclusion Criteria}

- Post catheterised patients

- Any chronic illness or risk factors

- Allergy or intolerance to cranberry

- Immuno compromised patients

- Pregnant women

- Patients not willing to participate in study

\section{Data Analysis}

All the data where entered into the Microsoft excel and analysed by Descriptive statistics. Clinical efficacy in the prevention of recurrent UTI was determined based on :

(1)Assessment of symptom improvement

(2) Microbiological evaluation

\section{Result}

Among the 20 patients selected, 17 patients fully completed the study, 2 patients failed to get follow up and 1 patient was excluded from the study due to recurrence of infection during the cranberry therapy. Within the remaining 17 patients, 13 patients showed positive outcomes to the therapy, while 4 patients showed recurrence of infection even after course of treatment .Thus the study suggests that about $76.4 \%$ of patients exhibited beneficial outcomes to the cranberry therapy in the prevention of recurrent UTI.

Table 1: Betterment and Recurrenc

\begin{tabular}{lc}
\hline RESULT & TOTAL NUMBER \\
\hline BETTERMENT & 13 \\
RECURRENCE & 4 \\
\hline
\end{tabular}




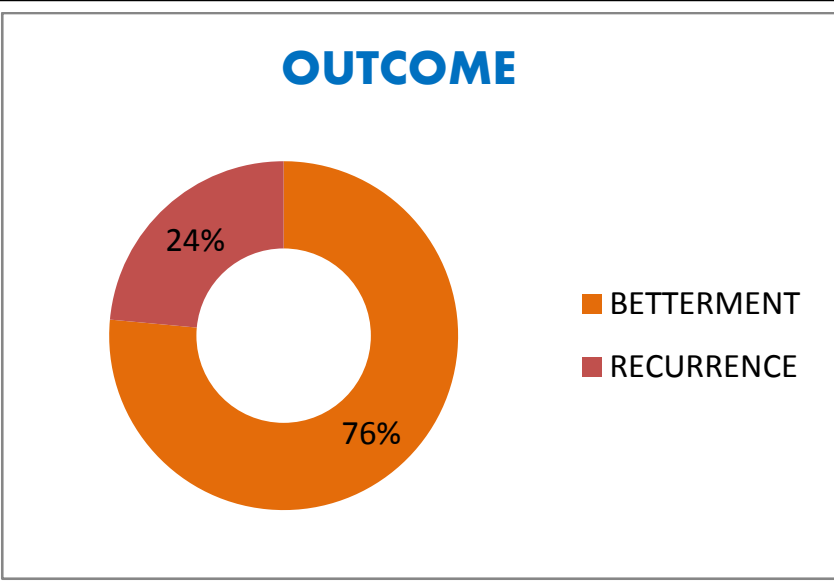

Figure 1

\section{Discussion}

UTI's are one of the most common bacterial infection seen in primary care, next to respiratory tract infections Although UTI'S affect both genders, women of the reproductive age group are the most vulnerable, may be due to their anatomy and reproductive physiology. Women are particularly at risk of developing UTI's because of their shorter urethra and certain behavioural factors which include delay in micturition, sexual activity and the use of contraceptives which promote colonization of the peri urethral area with coliform bacteria. Some evidence from the study suggest that cranberry juice and derivatives are effective in preventing the recurrence of UTI's. Studies from the Meta analysis and other studies suggest that cranberry products may be effective in women with recurrent UTI and elderly but do not appear to be effective in people with neuropathic bladder.

Through this study we found that among the people enrolled most of them (76.4\%) showed effective response to the cranberry therapy. E coli is usually the most prevalent organism responsible for UTI's .In this study also $60 \%$ of patients were found to be affected with $\mathrm{E}$ coli. Here the mean age of the selected patients was found as 50.1.

Through literature review it was found that most of the studies used symptoms assessment and microbiological evaluation as the tool for analysing outcome. Most of the studies were comparative as well as Trial studies but this study mainly emphasize on providing cranberry therapy for all the patients who satisfied the study criteria.At the initial visit lower abdominal pain was the most common symptom exhibited by the patients and it was severe for most of them. Frequency was the second most common symptom observed followed by burning pain. Voiding difficulty was the least observed symptom among the patient. Most of the symptoms improved during each follow up visits. During the final follow up, 4 patients showed worsening of their symptoms and showed recurrence. For most patients low back pain retained as at least mild. This may be related to their old age and certain other factors. For most patients who showed frequency and urgency in urination were having Diabetes Mellitus. For most patients the common risk factor was found to be decreased water intake, toilet unhygienic and one patient was found to have recurrent UTI after each periods.

On microbiological evaluation it was found that $\mathrm{E}$ coli was the most common pathogen causing UTI. The Culture report of 12 patients showed E coli as the pathogen where as in 4 patients P.Aeuruginosa, one patient was found to have $K$ Pneumoniae and 3 patients were having symptomatic abacteriuria. The increased higher number of E coli induced UTI can be because of the close proximity of the urethral catheter to the anal passage.

\section{Symptom Assessment at Initial Visit}

Table 2 Symptom Assessment at First Follow Up

\begin{tabular}{lcccc}
\hline SYMPTOM & NIL & MILD & MODERATE & SEVERE \\
\hline FREQUENCY & 6 & 5 & 8 & 1 \\
URGENCY & 13 & 5 & 2 & 0 \\
PAIN/ & 10 & 5 & 3 & 2 \\
BURNING PAIN & 15 & 2 & 3 & 0 \\
$\begin{array}{l}\text { VOIDING } \\
\text { DIFFICULTY }\end{array}$ & 0 & 9 & 11 & 0 \\
$\begin{array}{l}\text { LOWER } \\
\text { ABDOMINAL }\end{array}$ & & & & \\
PAIN & 13 & 3 & 4 & 0 \\
$\begin{array}{l}\text { LOW BACK } \\
\text { PAIN HEAMATIA }\end{array}$ & 20 & 0 & 0 & 0 \\
HEAMATIN & & & &
\end{tabular}




\section{JMSCR Vol||07||Issue||04||Page 1047-1052||April}

Table 3

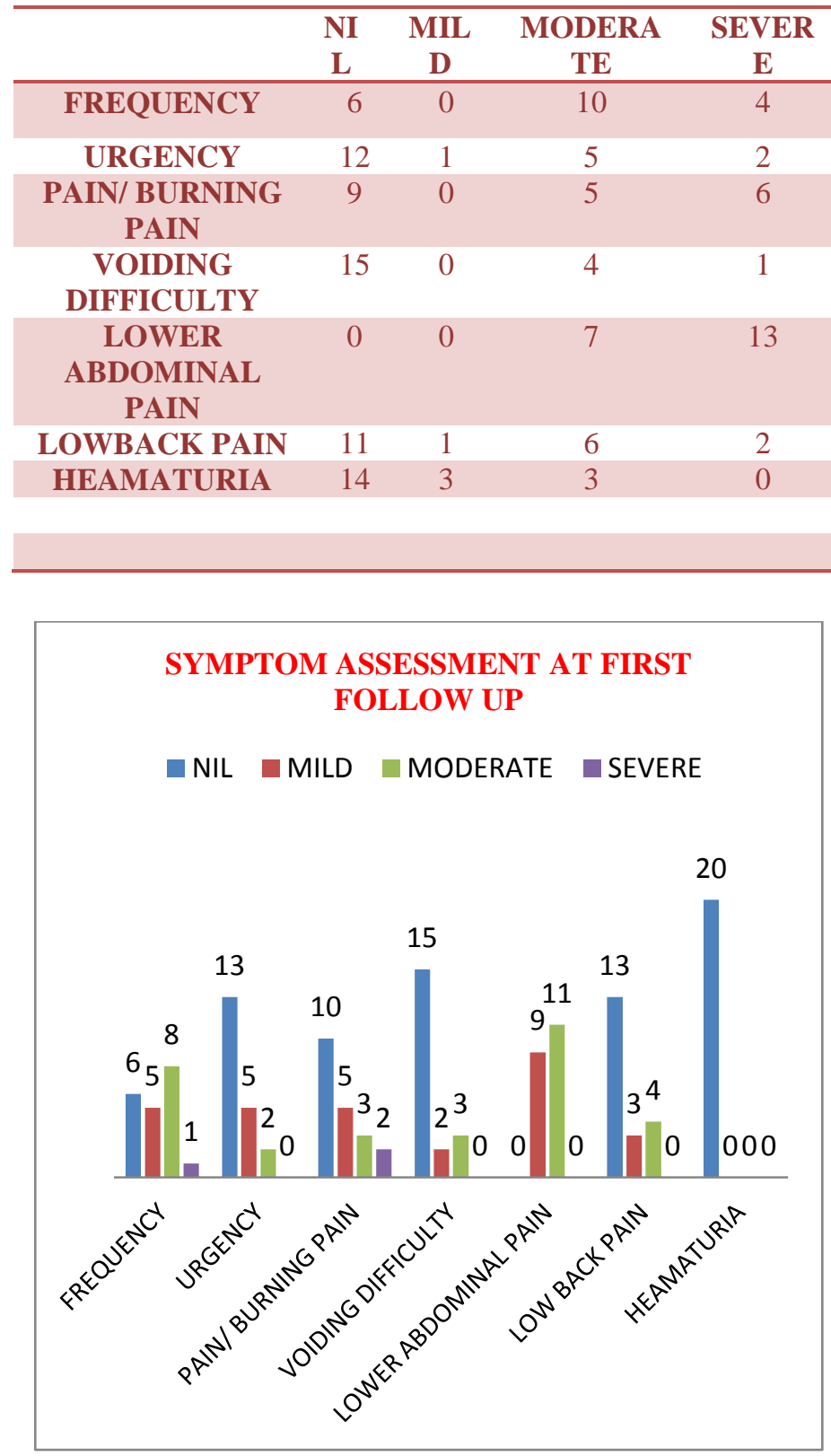

\section{Figure 2}

\section{Symptom Assessment at Second Follow Up}

Table 4

\begin{tabular}{lcccc}
\hline SYMPTOM & NI & MIL & MODERAT & SEVER \\
& L & D & E & E \\
\hline FREQUENCY & 5 & 7 & 4 & 1 \\
URGENCY & 13 & 2 & 2 & 0 \\
PAIN/BURNING & 13 & 3 & 1 & 0 \\
PAIN & & & & 0 \\
VOIDING & 13 & 2 & 2 & 0 \\
DIFFICULTY & & & & \\
LOWER & 2 & 14 & 1 & 0 \\
$\begin{array}{l}\text { ABDOMINAL } \\
\text { PAIN }\end{array}$ & & & & \\
LOW BACK & 10 & 5 & 2 & 0 \\
PAIN & & & & \\
HEAMATURIA & 17 & 0 & 0 & \\
\hline
\end{tabular}

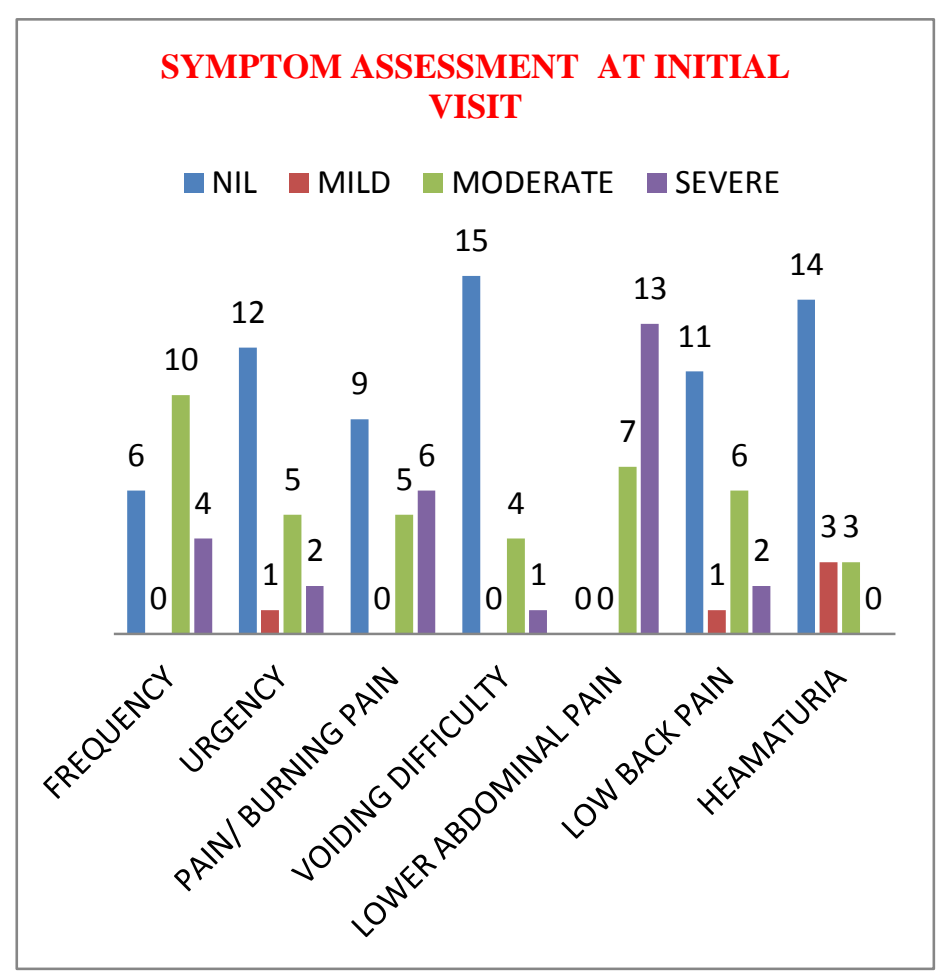

Figure 3

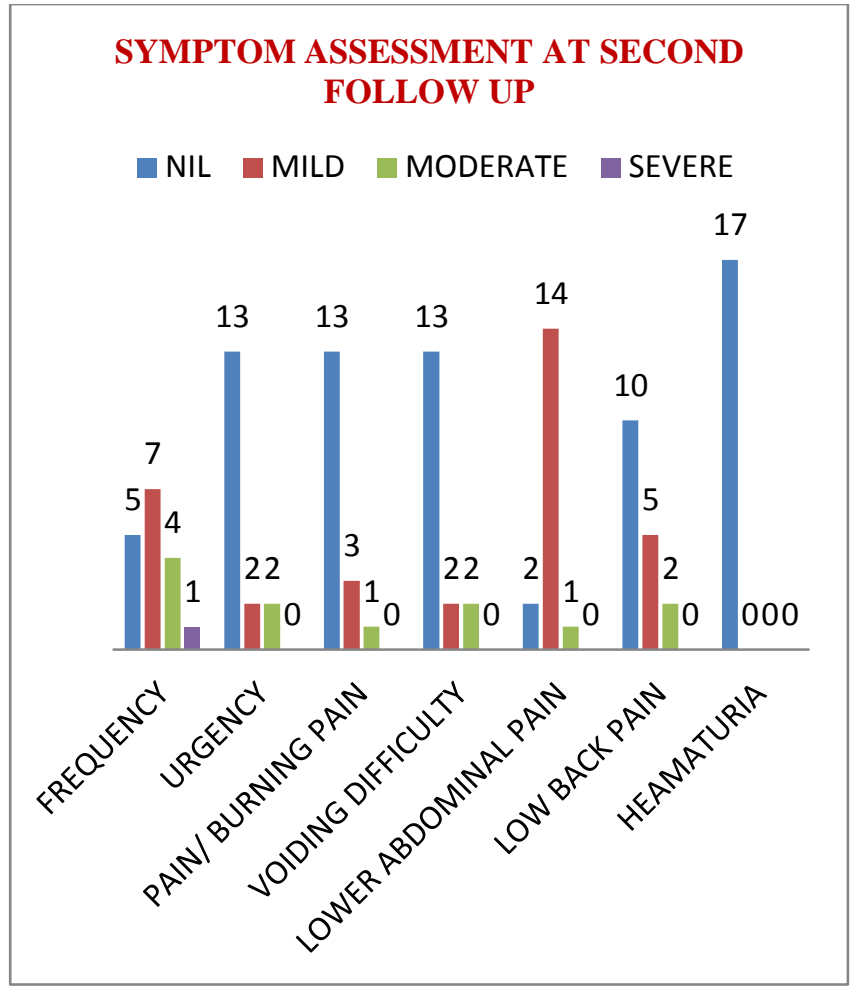

Figure 4 


\section{JMSCR Vol||07||Issue||04||Page 1047-1052||April}

Symptom Assessment at Third Follow Up

Table 5

\begin{tabular}{lcccc}
\hline SYMPTOM & NIL & $\begin{array}{c}\text { MIL } \\
\text { D }\end{array}$ & $\begin{array}{c}\text { MODERA } \\
\text { TE }\end{array}$ & $\begin{array}{c}\text { SEVER } \\
\text { E }\end{array}$ \\
\hline FREQUENCY & 7 & 9 & 1 & 0 \\
URGENCY & 12 & 4 & 1 & 0 \\
PAIN/BURNI & 14 & 3 & 0 & 0 \\
NG PAIN & & & & \\
$\begin{array}{l}\text { VOIDING } \\
\text { DIFFICULTY }\end{array}$ & 13 & 3 & 1 & 0 \\
$\begin{array}{l}\text { LOWER } \\
\text { ABDOMINAL }\end{array}$ & 9 & 6 & 2 & 0 \\
PAIN & & & & \\
$\begin{array}{l}\text { LOW BACK } \\
\text { PAIN }\end{array}$ & 10 & 5 & 2 & 0 \\
$\begin{array}{l}\text { HEAMATURI } \\
\text { A }\end{array}$ & 17 & 0 & 0 & 0 \\
& & & &
\end{tabular}

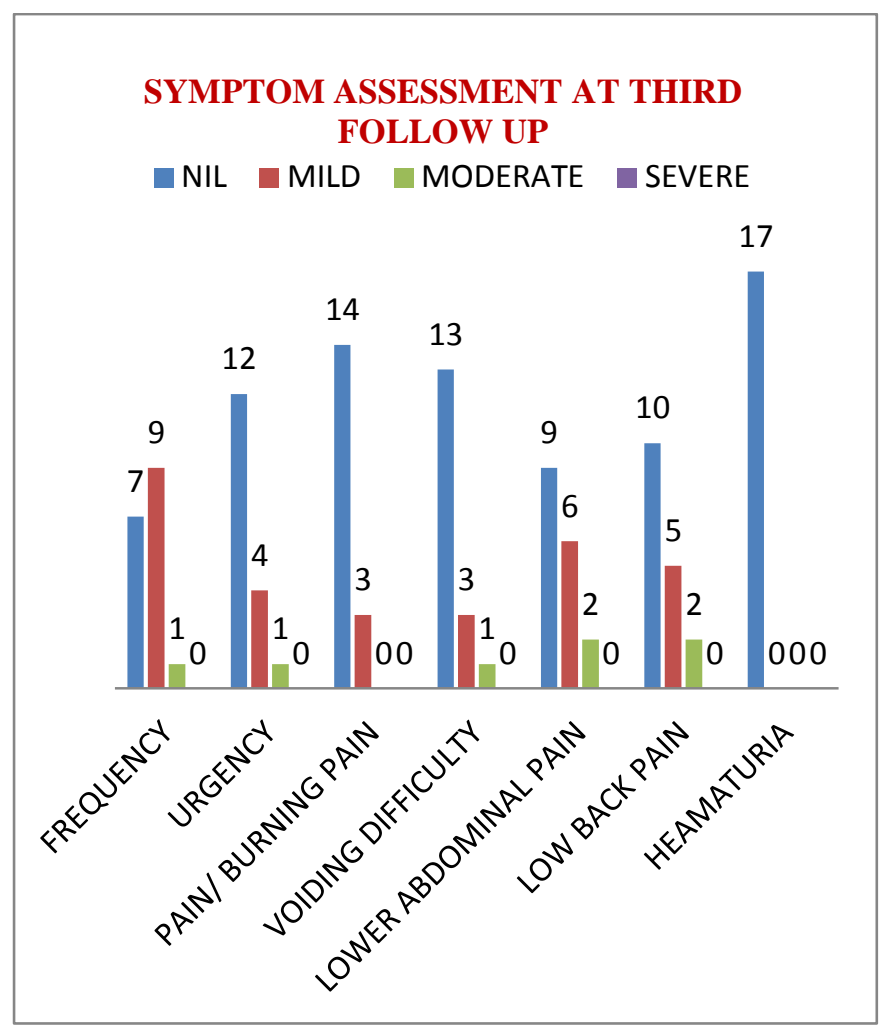

Figure 5
Symptom Assesment At Fourth Follow Up

Table 6

\begin{tabular}{lcccc}
\hline SYMPTOM & NI & MIL & MODERAT & SEVER \\
& L & D & E & E \\
\hline FREQUENCY & 10 & 5 & 2 & 0 \\
URGENCY & 13 & 2 & 2 & 0 \\
$\begin{array}{l}\text { PAIN/ } \\
\text { BURNING }\end{array}$ & 16 & 1 & 0 & 0 \\
PAIN & & & & \\
$\begin{array}{l}\text { VOIDING } \\
\text { DIFFICULTY }\end{array}$ & 15 & 1 & 1 & 0 \\
$\begin{array}{l}\text { LOWER } \\
\text { ABDOMINAL }\end{array}$ & 13 & 0 & 2 & 2 \\
PAIN & & & & \\
LOW BACK & 11 & 4 & 2 & 0 \\
PAIN & & & & \\
$\begin{array}{l}\text { HEAMATURI } \\
\text { A }\end{array}$ & 16 & 1 & 0 & 0 \\
\hline
\end{tabular}



Figure 6

\section{Microbiological Evaluation}

Table 7

\begin{tabular}{|l|c|}
\hline Organism & Number \\
\hline P aeuroginosa & 4 \\
\hline K pneumoniae & 1 \\
\hline Abacteriuria & 3 \\
\hline E coli & 12 \\
\hline
\end{tabular}




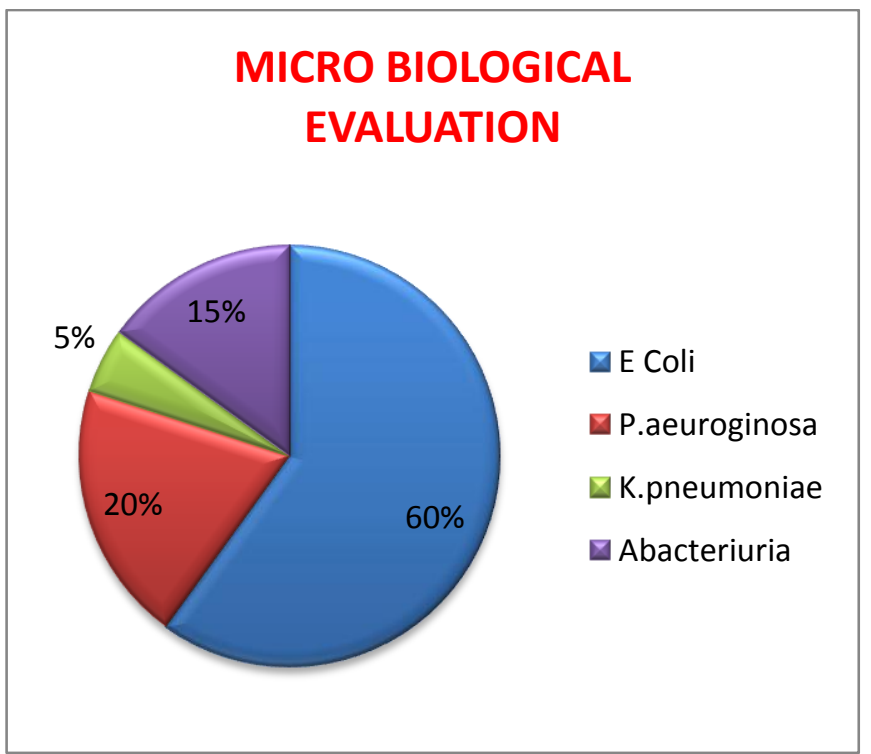

Figure 7

\section{Conclusion}

From the study it can be concluded that the cranberry supplements are found to be ,much effective in the prevention of recurrent UTI in female patients .But limited number of subjects and short follow up's were the limitations of the study, large and controlled study with a longer follow up's should be conducted for obtaining more evidence. A standardized dose and duration of cranberry supplements should be specified for the treatment.

\section{References}

1. Cranberry supplementation in the prevention of non-severe lower urinary tract infections: a pilot study; A. Ledda, A. Bottari, R. Luzzi, G. Belcaro, S. Hu, M. Dugall, M. Hosoi, E. Ippolito, M. Corsi, G Gizzi, P. Morazzoni1, A. Riva1, L. Giacomelli2, S. Togni1 :2015; 19: 77-80

2. Highly standardized cranberry extract supplementation (Anthocran ${ }^{\circledR}$ ) as prophylaxis in young healthy subjects with recurrent urinary tract infections ;A Ledda1, G. Belcaro1, M. Dugall1, A. Riva2, S. Togni2,R. Eggenhoffner3, L. Giacomelli3; 2017; 21: 389-393

3. Guay DR. Cranberry and urinary tract infections. Drugs 2009; 69: 775-807.

4. Howell AB. Bioactive compounds in cranberries and their role in prevention of urinary tract Infections. MolNutr Food Res 2007; 51: 732-737.

5. Cranberries and lower urinary tract infection prevention; Marcelo Hisano, I Homero Bruschini, I Antonio Carlos Nicodemo, II Miguel SrougiI; 2012;67(6):661-667

6. Howell AB, Foxman B. Cranberry juice and adhesion of antibiotic resistantUropathogens. JAMA. 2002; 287(23):3082-3

7. Stapleton A. Novel approaches to prevention of urinary tract infections. Infect Dis Clin North Am. 2003;17(2):457-71

8. Recurrent Urinary Tract Infections in Women: Diagnosis and Management ; Charles M. Kodner, Md, University Of Louisville School Of Medicine, Louisville, Kentucky Emily K. Thomas Gupton, DO, $\mathrm{MPH}$, Primary Care Medical Center, Murray, Kentucky;2010;82(6):638-643

9. Sheffield JS, et al. Urinary tract infection in women. Obstet Gynecol. 2005;106(5 pt 1):1085-1092.

10. Cranberry Reduces the Risk of Urinary Tract Infection Recurrence in Otherwise Healthy Women: A Systematic Review and MetaAnalysis; Zhuxuan Fu, 1 DeAnn Liska,2 David Talan,3 and Mei Chung1 